\title{
CREATING A TRIBAL CULTURE OF TRAFFIC SAFETY
}

\author{
MARGO L. HILL \\ Eastern Washington University, USA
}

\begin{abstract}
Transportation systems and travel behavior have a high social impact on communities in terms of safety and security. Native Americans across the USA and specifically in Washington State experience vehicular fatalities at four times the rate of average American citizens. Tribes can reduce the number of fatalities and serious injuries on their reservation roads if they implement best practices to influence their communities to take control over behaviors that cause fatal accidents, such as impaired driving, speeding and not using seatbelts. Tribal sovereignty empowers tribal governments to enact traffic codes and training programs that will work for their communities. Tribes face complex problems such as multi-layered governance structures and legal frameworks, traditional cultural behavior and underreporting of data. The Washington State Traffic Safety Commission funded Eastern Washington University (EWU) in 2014-15 and 2016-17 to develop a data-driven "Tribal Traffic Safety Demonstration Project" for six Washington State native tribes. Our EWU team developed a Tribal Traffic Safety Model to represent the complex interactions amongst the tribal programs and key stakeholders. We conducted dialogues with key tribal stakeholders to identify specific issues. We collected data on fatalities and mapped their location. We shared our findings with each tribe and provided examples of best practices. Our team interviewed key tribal staff personnel to assess existing codes, tribal court and law enforcement practices and tribal behavioral health treatment programs. Effective solutions emerge from data-driven planning and combined with tribal cultural teachings provide direction for tribal governments that cannot simply come from road engineering and traffic signage. Tribes can create traffic safety teams to work across Engineering, Emergency Medical Systems, Law Enforcement and Government Policies in order to improve traffic safety. Tribes are working to reduce fatalities and serious injuries but we have not seen significant reductions in traffic fatalities yet. This is an ongoing project.

Keywords: traffic safety, travel behavior studies, traffic fatalities, social impact, public policies and governance, impaired driving, American Indian.
\end{abstract}

\section{INTRODUCTION}

American Indian reservations and the roads leading to them have the highest rates of crashes, serious injuries and fatal crashes in the nation. Injuries are the leading cause of death for American Indian and Alaskan Natives ages 1 to 54 and the third leading cause of death overall [1]. Motor vehicle crashes are a leading cause of unintentional injury for American Indian and Alaskan Natives ages 1 to 44 [2]. Across America we also experienced an increase in Unintentional Poisoning, in which overdoses of prescription and illegal drug deaths surpassed unintentional motor vehicle deaths [3].

Eastern Washington University (EWU) undertook a demonstration project to work with 6 tribes across the state of Washington. The goal was to encourage tribal elected leaders, government staff, and the tribal nation to interweave a traffic safety culture into their community culture. The traffic safety focus of this paper will be on the behavioral aspects within the framework of Target Zero as applied to tribal communities. EWU worked to establish partnerships with selected tribes and provided an assessment of traffic collision data involving deaths and serious injuries. It was our goal to encourage the tribes to develop or improve, their systems for gathering and utilizing traffic collision data. EWU faculty and students created individual maps for the participating tribes. The team mapped all crashes 
and serious injuries on or near the reservations from 2010-2014. Due to unique travel patterns of tribal members we included a five-mile radius beyond the boundaries of the reservation. The EWU team completed an analysis of tribal traffic safety law and order codes and encouraged the use of Target Zero's data-driven approach to set priorities, implement select Target Zero proven strategies in transportation plans and programs.

\section{FEDERAL INDIAN LAW AND THE COMPLEXITIES TO TRIBAL TRANSPORTATION IN INDIAN COUNTRY}

Indian land ownership and who maintains title to tribal lands is important to traffic safety. Who is responsible for care and maintenance of the road and who responsible for patrolling a road often depends on who has title? Roads in Indian country can be tribal, state, federal (Bureau of Indian Affairs) or county. Indian Country is all land that is under the supervision of the U.S. government that has been set aside primarily for the use of Indians [4]. Most reservations were created by a treaty, statute or an executive order from a president. A tribe will hold ownership of the land but the title states that it is held in trust by the United States government for the specific tribe of Indians. This includes all land within an Indian reservation and land off reservation that is held in trust for a particular tribe for Indian use. As a general rule, state laws do not apply to Indians in Indian country; tribal and federal laws apply instead [5]. This unique jurisdictional framework makes it difficult to understand the complexities of Indian Country. When law enforcement gets a call for a crime that took place in Indian Country they must determine whether it happened on fee or trust property, whether the perpetrator was Indian or non-Indian and whether it was a Major Crime (e.g. Rape, Murder, Arson) to determine who has jurisdiction [6]. Moreover, tribe's do not have the right to exercise criminal jurisdiction over non-Indians [7]. This makes it difficult prosecute nonIndian impaired drivers that come onto the reservation.

There are 29 federally recognized Tribes in Washington State. Through the Centennial Accord, Tribes and the State of Washington have a formal agreement to work together on a government to government basis to solve problems such traffic fatalities and injuries. Tribal governments have sovereignty which is inherent sovereignty meaning they have the right to govern themselves. In Worcester vs. Georgia, the US government recognized that tribes have made decisions and governed their people since time immemorial. "Indian nations [are] distinct political communities, having territorial boundaries, within which their authority is exclusive" [8]. Indian tribes are sovereign political entities possessed of sovereign authority not derived from the United States which tribal people predate. Each tribe, on a case-by-case basis, has to contend with potential jurisdictional issues with local and state government entities when it concerns roads open to public travel [9].

\section{NATIVES KILLED AT HIGHER RATES THAN OTHER RACES}

According to the Washington State Strategic Highway Safety Plan 2016, Target Zero "From 2012 to 2014, 1,336 people lost their lives in motor vehicle crashes in Washington State" [10]. From 2012-2014, 63 American Indians and Alaskan Natives (AIANs) died in traffic crashes according to the national Fatality Analysis Reporting System (FARS) database. FARS records race and ethnicity from Washington Death Certificates and in Washington the traffic fatality rate for Native Americans is 3.0 times higher than the next highest death rate [11].

There are a number of challenges to track accurate data of fatalities on Indian reservations. "While nationwide data continues to be an issue, it is evident from the self-reported data from the tribes that alcohol impaired driving, speed, and non-use of seat belts play a significant role in fatal and injury crashes on the reservation" [12]. Tribal nations face many of the same 
traffic safety issues that the overall population does. However, there are 2 significant differences between the Tribal Target Zero Priorities and the overall Target Zero priorities which include: Unrestrained occupants are a priority 1 instead of priority 2 . Unlicensed drivers are a priority 1 instead of a priority 2 [13].

According to Washington State Highway Safety Plan 2016, American Indians and Alaskan Natives have higher death rates involving high risk factors than other races. For example, the rate of unrestrained vehicle occupant deaths per 100,000 population are more than 7 seven times higher than other races combined. The rate of AIAN getting killed due to impaired driving is 4.7 times higher than other races and AIAN pedestrian fatalities are 5.0 times other races. Lastly, AIAN are killed in traffic fatalities due to speeding at 4 times the rate of other races [14]. This data comes from NHTSA's Fatal Analysis Reporting System (FARS) as the baseline data source for tribal traffic safety data. Impaired driving, speed and non-use of seat belts are all things we as individuals have control over.

\section{CREATING A CULTURE OF SAFETY - 4 ES AND LEADERSHIP}

When EWU analyzed tribal traffic safety issues we considered the Four E's and Leadership as adapted from Target Zero: Education, Enforcement, Emergency Medical Services (EMS), Engineering and Leadership. Education requires that we give the tribal community the information to make good choices such as the actual data on how many tribal members are getting killed on their roadways. Inform the community of the dangers of driving while impaired by drugs and alcohol and promote positive decision making and norms of not driving while impaired. EWU worked with Law Enforcement to use a data driven analysis to help officers pinpoint locations with high number of injury collisions related to driver behaviors. With regard to Emergency Medical Services (EMS) we looked at how tribes integrate their health services with local counties and hospitals. EWU also worked with tribes to identify engineering issues such as design of roads, signage and shoulder width to discuss practical solutions to reduce collisions. Northwest Tribal Technical Assistance (NWTTAP) operated by EWU works with federal and state partners to offer workshops such as Road Safety Audits (RSAs) for tribes is northwest region. Lastly, we identified the role that tribal government leadership plays in traffic safety. In their legislative capacity, Tribal Councils have the power to pass law and order codes, ordinances, and resolutions. The team analyzed law and order code provisions, identified staffing issues and worked to provide tribal council strategies to improve tribal programs and tribal policies. "Tribal communities expect that their own patterns of travel and movement, their own pace of life, that of wildlife, pathways and culture, will provide guidance for plans and projects on tribal lands. Tribal Transportation plans must maintain cultural integrity [15]."

In the first part of this project, the team learned that 4Es and leadership wasn't enough. Tribal governments need a change across the whole tribe to build a culture of safety. Tribal programs and staff cannot simply work in individual silos but rather must create a culture of safety by working across all tribal programs and form a tribal traffic safety committee. All of the top contributing factors of reservation fatalities involve behavioral issues around habits, patterns of driver education and experience, and driver perception of punishment or determent to the community by not following traffic codes, as well as the effectiveness and impact of tribal codes on tribal members and the community. EWU created the Tribal Transportation Safety Model to identify all the key stakeholders in transportation safety. This is a complex system of interaction and individual relationships, resources and responsibilities with each stakeholder being expected to do their part. We have placed the tribal member behavior choices at the center of the model because we know that traffic safety is peoplecentric. Human factors include why did the crash happen? What factors were involved such 
as speed or impairment? Were they wearing a seatbelt? It is human choices and behavioral issue related to addiction that lead to impaired driving.

\section{TRIBAL BEHAVIORAL ISSUES: CONTRIBUTING FACTORS TO ADDICTION ON THE RESERVATION - THE PERFECT STORM}

Alcohol and drug addiction affects all communities across American but is particularly harmful in some segments of tribal communities. A large number of tribal members are clean and sober. However, the segments of the population that do drink do so at a more intense rate. May recognized that they consume extremely high quantitates when they do drink [16]. Binge drinkers experience many alcohol related consequences with accidents being the most common [17]. Beauvais [18] reported similar drinking patterns among Indian adolescents [18]. To reduce the number of impaired driving fatalities we must understand addiction and risk factors.

In his book "Addiction and Change" Dr. Carlo Clemente discusses a number of chemical dependency theories to identify contributing factors of addiction that we can apply to native nations. The social/environmental perspective emphasizes the role of societal influences, peer pressure, social policies, availability (of drugs) and family systems as a mechanism responsible for the adoption and maintenance of addictions [19]. Certain types of drug use and individual addictive behaviors occur more frequently in some subgroups. This has encouraged researchers to examine subculture related to drug use [20]. In tribal communities, we see young people drinking at an early age due to social influences such as family and friends. These social connections are powerful in tribal communities. Lead-in drug use is

\section{Spokane Tribe of Indians \\ Tribal Transportation Safety Model}

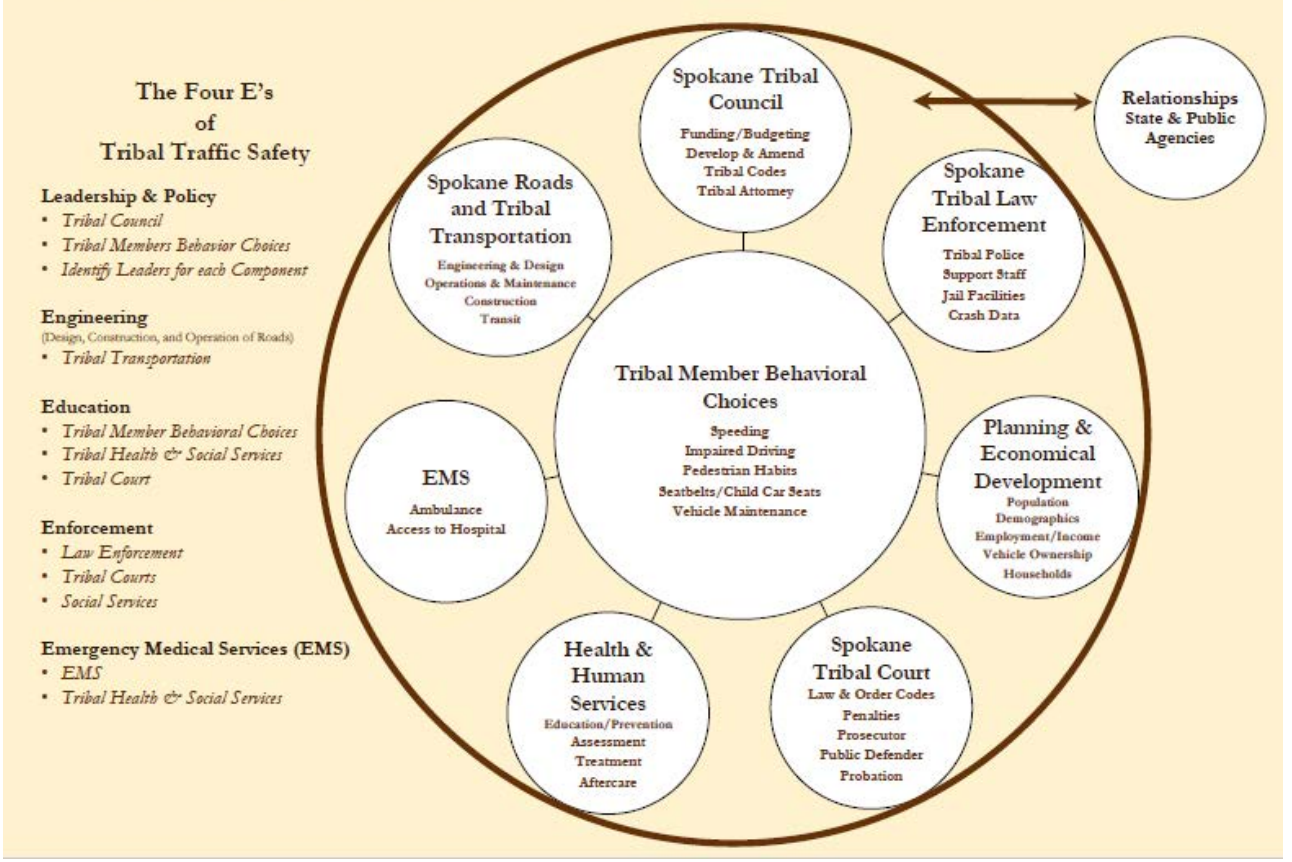

Figure 1: Tribal transportation safety model for the Spokane tribe of Indians. 
often facilitated by older cousins which is highly damaging to brains who have not matured yet. Advocates of family explanations point to problematic parental modeling of adult roles that can include difficulties with relationships, conflicted and broken marriages, and excessive use of alcohol and other drugs on the part of the parents as important influences on the child's experimenting with and continuing an addictive behavior [21].

Another explanation of addiction lies in the role of genetics. "Family studies indicate increasing risk ratios for individuals as the number of alcoholic relatives rises and as the number and severity of familial alcohol problems rise [22]." Alcohol and substance abuse is a significant factor in tribal communities. The physiological model of dependence is better understood today. As Clemente explains the traditional markers that define drug dependence were both tolerance and the need for more of a substance to achieve the same effect - and a clear withdrawal syndrome, which included physical reactions like nausea and a craving for the substance [23]. Tribal members addicted to prescription pain pills have reported feeling very sick when they didn't have their drugs. They began to look for available or cheaper alternatives and many turn toward heroin. Another theory for addiction is the Coping and Social Learning Model. Clement states that "often addictions are considered to be the result of poor coping mechanisms. Unable to cope with life stresses, addicts turn towards their addiction for escape or comfort [24]. Tribal community members deal with a number of stressors such as poverty (inability to pay bills), relationship let downs (parents or spouse) and violence. Thus, it is highly likely that tribal members will drink to deal with a stressful even as a coping response. A better understanding of addiction can help tribal communities come up with strategies to reduce impaired driving.

\section{CASE STUDIES: WHAT TRIBES IN WASHINGTON ARE CURRENTLY DOING TO COME UP WITH BEHAVIORAL STRATEGIES TO REDUCE IMPAIRED DRIVING AND COUNTERMEASURES IN EACH PROGRAM AREA}

The American Indian and Alaska Native population is disproportionately represented in fatalities and crash statistics in many states [25]. According to the Centers for Disease Control, motor vehicle crashes are the leading cause of unintentional death for American Indians and Alaska Natives (AI/AN) ages 1-44 [26].

NHTSA provides a Highway Safety Countermeasure Guide [27] which identifies four basic strategies that are used to reduce alcohol-impaired crashes and drinking and driving:

- Deterrence: enact, publicize, enforce and adjudicate laws prohibiting alcoholimpaired driving so that people choose not to drive impaired;

- Prevention: reduce drinking and keep drinkers from driving;

- Communications and outreach: inform the public of the dangers of impaired driving and establish positive social norms that make driving while impaired unacceptable; and

- Alcohol treatment: reduce alcohol dependency or addiction among drivers.

The aim of this paper is to discuss countermeasures tribes are currently utilizing, ones they are leaving on the table and tribal cultural strategies that are also implemented.

Deterrence means enacting laws and programs that prohibit impaired driving and providing consequences and monitoring of those offenders. All 6 of the tribes located in Washington State that EWU worked with implemented tribal laws that define impaired driving and set illegal limits at $0.08 \mathrm{BAC}$ (blood alcohol concentration) and provide penalties for impaired driving. It can be difficult to detect impaired drivers. Tribal law enforcement 
agencies are very short staffed and have limited resources. On the Confederated Tribes of Colville Indian Reservation, a large land based tribe, law enforcement is responsible for patrolling 1.4 million acres and are often short staffed. To stop impaired drivers, law enforcement have to witness a traffic violation or other dangerous behavior before they can stop a vehicle. Once they've stop a vehicle it can be difficult to detect whether an individual is impaired. For example, if an individual is drugged driving they may not have red eyes or the odors associated with alcohol intoxication. Moreover, there is no easy roadside detection test similar to a breathalyzer for prescription or illegal drugs. This makes the enforcement of driving under the influence (DUI) very complicated and difficult to get the evidence needed to demonstrate impairment. Law enforcement officers have to get search warrants to collect blood. Currently, law enforcement transport offenders to hospital to draw blood. Police departments in Washington State are undergoing phlebotomist certification. According to Darrin Grondel of the Washington State Traffic Safety Commission, it currently takes police officers 139 minutes to process a DUI with a breathalyzer. It takes 239 minutes to process a DUI when a blood draw is required.

Under tribal jurisdiction, the DUI control system is complicated as tribe's do not have criminal jurisdiction over non-Indians [28]. This requires tribal police to contact the local county sheriff and detain offender until local jurisdiction can make arrest. There are many situations in which the system breaks down and it allows for impaired drivers to go without consequences. In the past, tribal law enforcement would give a drunk driver a ride home and make them park their car to keep them off the roadway. Today tribal councils like the Lummi Nation are directing law enforcement to arrest drug dealers and drunk drivers [29].

In working with the 6 tribes, deterrence takes all relevant tribal programs doing their part: enforcement (police), prosecution, adjudication (tribal court) and offender monitoring (probation). These key stakeholders working together to provide consequences, treatment and monitoring are the most important aspect of deterring repeat impaired driving. Tribal staff encountered a number of problems while monitoring offenders and providing treatment. Having an efficient and effective DUI management system helps provide consistent consequences to tribal offenders. One tribal treatment provider found it challenging to provide services due to tribal member mobility patterns. Tribal members often move from one reservation district to another and paper files are difficult to manage. Some rural reservations do not have consistent reliable internet and make digital files problematic.

It is important to track each DUI offender from arrest through the completion of all sentencing requirements by the court [30]. Each tribe is different and as sovereign nations can design and implement tracking and deterrence systems in any manner they choose. The Lummi Tribe of Washington State has enacted a "Swift and Certain" program which tracks offenders. Probation officers complete home visits and UAs (urinalysis). Urine may be tested to determine whether an individual has engaged in recreational drug use. Some tribal probation officers can perform urinalysis by using urine test strips, in which the test results can be read as color changes. In state court systems, community corrections professionals and agencies face challenges to the supervision of DUI offenders. For example, community corrections caseloads often are inordinately high, making it difficult for staff to provide adequate supervision to offenders [31].

This is the case with the many tribes in Washington and the result is probation officers have too many clients to monitor. Another tribe decided to take a more traditional tribal approach. Their probation officers do not do home visits but meets with clients and meets with jail inmates and makes a cultural connection. The probation officer brings the inmates outside to the courtyard and will pray with the young men. She explained that when you are outside with nature you pray and use the sweet grass. This traditional tribal approach included 
the recognition of cultural knowledge of offender's family such as parents and grandparents. The probation officer recognized that one individual came from a tribal family that drummed so the inmate was asked to explain to the group the protocol for sitting at a drum and to lead the group in a tribal song. The offender explained traditional practices of drum and felt empowered by sharing his family and tribal knowledge. Another offender was asked if they would like to go back and join the longhouse? Tribal tradition dictates that you be clean and sober to join the drum line at the longhouse. He said yes. That he would like to be clean and sober and join is family and tribe in the drum line. By utilizing traditional tribal knowledge, the probation officer had a positive cultural interaction with the offender.

Studies have shown that you need an efficient and effective DUI control system [32]. It is important to have adequate resources for staff, training, equipment and technology; and coordination and cooperation across all components from arrest to treatment to jail.

\section{OTHER COUNTERMEASURES - BEST PRACTICES}

A number of countermeasures available are met with resistance or prove to be too problematic. As mentioned, Tribal Councils have the power to pass law and order codes, ordinances, and resolutions. For example, if a code is not clear that seatbelts are primary or secondary offense, then tribal police are not likely to issue tickets. A "Best Practice" as identified by research is the Lummi Business Council which amended the law and order code that now mandates seatbelt use. Tribal law enforcement now pulls over and tickets community members not wearing their seatbelts. Many of the Tribal Law \& Order Codes are lacking in clear sentencing guidelines for driving under the influence (DUIs). However, a "Best Practice" utilized by the Swinomish was to provide clear sentencing guidelines for repeat offenders and high BAC (Blood Alcohol Concentrations). The Swinomish code require judges to state in writing their reasons if they do not impose the minimum sentence required by tribal code.

Another problem for rural tribal communities is access to driver's education programs for tribal youth. Young adults lack access to driver's education programs on the reservation so they are not getting driver's education or their licenses. Financial barriers also exist because parents and young adults have to travel over an hour off reservation to get to a driver's education location. The Nooksack Tribe in western Washington had their own tribal employees get trained as driver's education instructors and are working to make it more accessible to tribal communities.

There are a number of countermeasures that tribes do not fully utilize such as Administrative License Revocation/Suspension and Alcohol Ignition Interlocks for impaired driving. Many tribes do not report their DWI/Impaired driving offenses to the state licensing authorities to suspend a driver's license. Tribal courts can suspend driving privilege on the reservation, as well as, allow offender to obtain an occupation or hardship license in lieu of full suspension. Since there is often extreme poverty in Indian Country, tribal leadership does not want to suspend driver's license and risk the tribal member's employability. One tribal member, who is also an engineer, suggested a traditional punishment in which tribes enact code provision that suspend hunting and fishing rights if the tribal member continues to drink and drive. The number of impaired driving offenses on reservation roads continues to be excessively high. This is complicated by inconsistent application of the laws or ineffective consequences. However, some tribes did report DWI to the state if it was their second or third offense. For example, the Lummi Tribal Police arrest people for driving under the influence of alcohol and drugs. After three DUIs, violators are reported to the Washington State Department of Licensing. As mentioned previously, it can be difficult for tribal law enforcement to distinguish different types of drug impairment. The Suquamish tribal police 
have gone to the extra time and expense to have Suquamish tribal police get certified as Drug Recognition Experts (DREs).

One countermeasure that tribes could benefit from is Alcohol Ignition Interlocks. An alcohol ignition interlock prevents a vehicle from starting unless the driver provides a breath sample with a BAC lower than a pre-set level. Interlocks typically are used as a condition of probation for DWI offenders, to prevent them from driving while impaired by alcohol [33]. These interlock devises have proven to be very effective. However, there are a number of barriers to utilizing interlock technology in rural areas such as reservation communities. Access to interlock service providers may be limited or non-existent in rural jurisdictions, requiring offenders to drive long distances to get an interlock installed or services. It is very cost prohibitive for tribe's to even consider requiring interlocks for offenders. Community members can't afford to drive an hour every month to pay the fee to have the devices recalibrated.

For native people, it is important to include a cultural and spiritual element in the punishment, treatment and recovery process. The Colville Tribe as well as the Yakama nation allow for jail inmates to participate in tribal spiritual ceremonies such as the sweat house. Inmates pray and sing tradition tribal songs to help heal their spirit. There are also a few tribes who have economic development due to gaming operation have built their own drug and alcohol treatment facilities. The Tulalip Tribe has a clean and sober recovery house. They provide recovery coaches and their facility is surround by tribal art and tribal cultural practices. They have traditional salmon cooking pits and the community donates the wood and salmon for the client to bake.

\section{CONCLUSION}

EWU continues to work with tribal elected leaders, government staff, and the public to interweave an enduring traffic-safety culture into their community culture. We are working with tribes to develop the necessary action plans to respond to the devastating and unacceptable data. Traffic safety which utilizes behavior change to reduce roadway deaths and serious injuries, needs to be established within tribal governments. Effective solutions from tribal cultural teachings, not simply from road engineering and traffic signage need to be implemented. Each tribe should structure a Safety Action plan in terms of their tribal culture and their own patterns of travel and movement. Tribes need to develop a tribal culture of traffic safety - react in a culturally appropriate manner to our own pathways and ways of life. Each tribe is a sovereign government and can make decisions for the best interest of their citizens. Tribes can take action based on sovereignty and they must recognize that the fatality rates are unacceptable and provide solutions. Each tribal nation should recognize that the contributing factors are behavioral and their membership can have control over them. Tribal traffic safety committees can concentrate on behavioral change on roadway users to reduce traffic deaths and serious injuries, and encourage collaboration with all traffic safety disciplines. Tribal governments can find solutions and take action based on sovereignty.

\section{ACKNOWLEDGEMENTS}

This project was supported by a grant from Washington State Traffic Safety Commission (WTSC). The author is grateful to the Washington state tribes that participated in this demonstration project.

\section{REFERENCES}

[1] Centers for Disease Control (CDC). National Center for Injury Prevention and Control Web Site, Washington DC, Online. https://www.cdc.gov/. Accessed on: 12 Jun. 2017. 
[2] Centers for Disease Control (CDC). (2014). Roadway to Safer Tribal Communities Toolkit, Motor Vehicle Safety. Centers for Disease Control Injury Center, Online. http://www.cdc.gov/motorvehiclesafety/native/toolkit.html. Accessed on: 12 Jun. 2017.

[3] Murphy, T., Pokhrel, P., Worthington, A., Billie, H., Sewell, M. \& Bill, N., Unintentional Injury Mortality Among American Indians and Alaskan Natives in the United States, 1990-2009. AJPH 2014:104-S3:S470-S480.

[4] Pevar, S., The Rights of Indians and Tribes, Oxford University Press: Oxford and New York, pp. 20-21, 2012.

[5] Pevar, S., The Rights of Indians and Tribes, Oxford University Press: Oxford and New York, pp. 20-21, 2012.

[6] Major Crimes Act, 18 U.S.C. $\$ 1153$.

[7] Oliphant v. Suquamish Indian Tribe, 435 U.S. 191.

[8] Worcester v. Georgia, 31 U.S. 515, 517, 557, 559, 1832.

[9] Hill, L.M. \& Myers, C., Creating A Culture of Traffic Safety on Reservation Roads: Tribal Law \& Order Codes and Data-Driven Planning. Indigenous Peoples' Journal of Law, Culture \& Resistance, 3, pp. 43-80, 2015-2016.

[10] Washington State Strategic Highway Safety Plan 2016: Target Zero. p. 2, 2016.

[11] Washington State Strategic Highway Safety Plan 2016: Target Zero. p. 178, 2016.

[12] BIA Indian Highway Safety Program FY 2015 Highway Safety Plan, p. 12.

[13] Washington State Strategic Highway Safety Plan 2016: Target Zero, p. 182, 2016.

[14] Washington State Strategic Highway Safety Plan 2016: Target Zero, p. 181, 2016.

[15] Winchell, D. \& Rolland, R., Tribal Transportation Guidebook, Eastern Washington University, Washington State Department of Transportation, and the Tribal Transportation Planning Organization (TTPO), 2009.

[16] May, P., The prevention of alcohol and other drug abuse among American Indians: A review and analysis of the literature. In: P. Langton, ed., The Challenge of Participatory Research: Preventing Alcohol-Related Problems in Ethnic Minority Communities, DHHS Pub. No. (SMA) 95-3042, Center for Substance Abuse Prevention: Washington, DC, pp. 183-244, 1995.

[17] May, P., Overview of alcohol abuse epidemiology for American Indian populations. In: Sandefur, G., Rindfuss, R. \& Cohen, B. eds., Changing Numbers, Changing Needs American Indian Demography and Public Health. National Academy Press: Washington, DC, pp. 235-261, 1996.

[18] F. Beauvais, ed., Indian adolescent drug and alcohol use: Recent patterns and consequences [Special Issue]. American Indian and Alaska Native Mental Health Research, 5(1), pp. 1-78, 1992.

[19] DiClemente, C.C., Addiction and Change, How Addictions Develop and Addicted People Recover, The Guilford Press: New York and London, p. 7, 2003.

[20] Johnson, B.D., Toward a theory of drug subcultures. In D.J. Letteri, M. Sayers, \& H.W. Pearson (eds), Theories on drug abuse; Selected contemporary perspectives (NIDA Research Monograph (30), pp. 110-119, DHHS Publication No. ADM 80-967), National Institute on Drug Abuse: Washington, DC, 1980.

[21] Chassin, L., Curran, P.J., Hussong, A.M. \& Colder, C.R., The relations of the parent alcoholism to adolescent substance use; A longitudinal follow-up study. Journal of Abnormal Psychology, 105, pp. 70-80, 1996.

[22] Shuckit, M.A., A long-term study of sons of alcoholics. Alcohol Health and Research World, 19, pp. 172-175, 1995. 
[23] DiClemente, C.C., Addiction and Change, How Addictions Develop and Addicted People Recover, The Guilford Press: New York and London, p. 10, 2003.

[24] DiClemente, C.C., Addiction and Change, How Addictions Develop and Addicted People Recover, The Guilford Press: New York and London, p. 13, 2003.

[25] Washington, S.O., (2013), Washington's Target Zero, Online. http://www.targetzero.com/PDF2/targetzero2.pdf. Accessed on: 7 Jul. 2016.

[26] Centers for Disease Control and Prevention (CDC), 2014.

[27] Goodwin, A., Thomas, L., Kirley, B., Hall, W., O’Brien, N. \& Hill, K., Countermeasures that work; A highway safety countermeasure guide for State highway safety offices, Eighth edition (Report No. DOT HS 82 202), National Highway Traffic Safety Administration: Washington, DC, 2015.

[28] Oliphant v. Suquamish Indian Tribe, 435 U.S. 191.

[29] Interview Lummi Chief of Police, July 16, 2015.

[30] Goodwin, A., Thomas, L., Kirley, B., Hall, W., O’Brien, N. \& Hill, K., Countermeasures that work; A highway safety countermeasure guide for State highway safety offices, Eighth edition, (Report No. DOT HS 82 202), National Highway Traffic Safety Administration: Washington, DC, pp. 1-10, November.

[31] Hedlund, J.H. \& McCartt, A.T., Drunk driving: Seeking additional solutions, Preusser Research Group: Trumbull, CT, 2002.

[32] Robertson, R.D., \& Simpson, H.M.,DWI system improvements for dealing with hard core drinking drivers: Monitoring, Traffic Injury Research Foundation: Ottawa, Ontario, Canada, 2003.

[33] Goodwin, A., Thomas L, Kirley, B., Hall, W., O’Brien, N. \& Hill, K., Countermeasures that work; A highway safety countermeasure guide for State highway safety offices, Eighth edition, (Report No. DOT HS 82 202), National Highway Traffic Safety Administration: Washington, DC, pp. 1-38, 2015. 